IFIAS:

\section{the top people's problem posers}

The International Federation of Institutes for Advanced Studies aims to mobilise a global intellectual community to examine problems which have not been officially recog. nised and subjected to political convenience. Wendy Barnaby reports.

$\mathrm{T}_{\mathrm{s}=\mathrm{sen}}^{\mathrm{n}}$ HE last few years have seen an upsurge in discussions about the social responsibilities of scientists. From Koestler's "Callgirls" to articles in the daily press, the familiar message has been that science is not an activity which should be broken up into discrete categories and carried on in laboratories isolated from moral issues and awareness of the directions in which societies are developing. Such sentiments have already-unfortunatelybecome platitudinous. So it is rather a shock to discover a potentially highpowered organisation which exists to put them into action.

The International Federation of Institutes for Advanced Study (IFIAS) is a loosely-structured conglomeration of some twenty research institutes in sixteen countries. It is a unique federation because the institutes cover at least ten very different disciplines and cooperate on scientific projects which they hope will contribute to the solution of some of our global problems.

The federation was set up in 1972 with $\$ 90,000$ in equal grants from the Nobel, Rockefeller and Swedish State Bank Foundations. It is non-profit making, and non-governmental, with headquarters at Stockholm in three small rooms in the Nobel House, where its secretary, Dr Sam Nilsson (a physicist), also lives. Its structure and methods of working are very flexible: it is not so much an organisation, says $\mathrm{Dr}$ Nilsson, as a lack of organisation. General guidance on the course to be followed and on specific projects is given by the directors of the member institutes, a board of trustees (whose Chairmen are Drs Alexander King (UK), Paul M. Fye (USA), Abdus Salam (Pakistan) and Victor Urquidi (Mexico)), and a panel of advisers in different fields who have participated in IFIAS work. The secretariat is the go-between for the institutes, and initiates and catalyses new projects. It has been supported, after the exhaustion of the initial funds, by
$\$ 150,000$ a year, a sum made up of annual fees from member institutes, each of which pays $0.5 \%$ per 1,000 units (whether dollars, yen, rupees or whatever) of its operating budget, and grants to be paid for 5 years by foundations and similar bodies in Sweden ( $\$ 35,000$ each year), USA (also $\$ 35,000)$, Japan $(\$ 10,000)$, Italy $(\$ 5,000)$ and France $(\$ 5,000)$. Each institute taking part in a project also pays a levy of $10 \%$ of its contribution to the project. These levies are the secretariat's third source of income.

The institutes themselves specialise in fields including oceanography, medicine, physics, humanistic studies, economics, ekistics (the study of human settlements), genetics, international relations, rice research, mathematics and insect physiology and ecology. Together they represent 5,000 researchers and over $\$ 100$ million in annual expenditures.

IFIAS' intention is to mobilise this global intellectual community to examine problems which have not been officially recognised and subjected to political convenience. It is the belief of the federation that more effective communication must be stimulated between, on the one hand, those who make the decisions involving long-term consequences for mankind, and, on the other, the world's intellectual and spiritual leaders. By choosing as-yet politically-uncontaminated areas of study, and by consulting and involving the decision makers in projects from the very beginning, IFIAS hopes to bring the influence of facts and wellconsidered alternatives to bear on the decision makers when they have to act. The emphasis is on working with decision makers rather than presenting them with tomes of conclusions which will never be read. By making use of the contacts of its members, the federation has been able to adopt a policy of dealing only with top people, whether politicians, bureaucrats, businessmen or scientists, and so has a greater potential for influence than most organisations.

Specific action requires a specific focus. Every project is therefore concrete, complex, budget- and timelimited, global in scope and involving inter-disciplinary research. Participation in projects is not limited to member institutes. Other research bodies take part when their expertise is needed, and in this way various UN agenciesUNESCO, WHO, the UN Environment Programme (UNEP) and the World Meteorological Association (WMO)are involved in different projects. No proposal for a new project is accepted before it has been extensively screened at workshops to make sure that nobody else is doing it better, that at least two member institutes from different countries are willing to assume responsibility for it, that a specific scholar is willing to lead it, and that it has social, ethical and humanistic implications and financial support. When a topic is first accepted, IFIAS sets up a programme of activity which may or may not develop into a fullscale project. So far, funding has come from the World Bank, Volkswagen, the Ford and Rockefeller Foundations, UNEP, UNESCO and the Swedish agency for aid to developing countries (SIDA). To promote contacts with those who wield power over hundreds of thousands of lives, and to attract funds, IFlAS has also begun to approach international corporations.

The programmes and projects so far in operation are:

- Impact of climate changes on the character and quality of human life (budget: \$300,000)

- Human settlements: understanding their nature and guiding their development for the benefit of man $(\$ 325,000)$

- Socio-economic and ethical implications of enzyme engineering $(\$ 194,000)$

- Energy and quality of life $(\$ 80,000)$. These programmes and projects are being screened:

- Options for regions faced with water shortage

- Interaction of health, nutrition and education on human growth and development

- Loss of productive soil

- Third world: cultural transfercultural change

- Independence and interdependence in the face of regional collapses.

The projects are not concerned with research which gives rise to predictions about resources, climate changes or urbanisation for example. As Dr Nilsson points out, there is a wealth of such predictions already. IFIAS sees its task as examining their consequences. The human settlement project starts from the prediction that by the year 2000 , $50 \%$ of the estimated world population of 6.5 billion will live in cities. The rationale of the project is that, as these cities will be built anyway, they should be planned in order to conserve resources and promote the best possible living conditions for their inhabitants.

The project aims to draw up a classification of human settlements and, through case studies from Sweden, France, Mexico, India, USA, Columbia and Argentina, to establish criteria for understanding their development. It is hoped that the project will arrive at a conceptual framework which could point to practical suggestions for the UN Conference-Exposition on human settlements (HABITAT) to be held in Vancouver next year.

The project on climatic change is 
being carried out against the background of predictions that climatic alterations will soon threaten existing systems of food production. In the face of conflicting predictions about the changes and their effects, the project has adopted the general IFIAS method of dealing with a range of predictions varying from the least to most drastic. What is 'drastic' to begin with is then defined by the general criteria for project selection, mentioned above. The researchers are aiming for plans and actions to establish the technical, social and political means to cope with different climatic threats to food.

The energy programme is in two parts. The first is concerned with energy analysis, which is the idea of working out how much energy is embodied in goods or services, expressed as physical units. Undertaken in the light of predictions that, because of limited resources and extravagant use, energy may become a severely limiting factor in many sectors of society, energy analysis includes not only the direct energy used for fuel and to run machinery, but also the energy required to make available each of the input materials. For example, in an industrialised country a loaf of bread is the end product of seed which grows through the absorption of energy (partly from natural sources, partly from petroleum made into fertiliser) into grain, which is harvested, transported and processed into flour by machines, then transported again and added to other ingredients (all of which have arrived at this point through similar processes), mixed and baked by more machines into bread (which is possibly wrapped in paper that is the end product of another energy-consuming chain), and finally transported by petroleum-eating lorries to the supermarkets.

Because energy analysis is value-free, it can provide information, in addition to the predictions of our all-too-fallible economic theories, for decision making. It appears to be neither costly nor difficult to carry out, as much of the data needed already exist in national statistics, industrial process data and various other sources. The urgent need is for a common set of rules for calculating energy inputs and transformations, and for common terminology, symbols and units of measure. It is these that the IFIAS project is drawing up.

Once the tools are agreed upon, researchers in different countries will be able to calculate the energy inputs into similar products and identify steps where the use of energy could be reduced. Or the analysis could be used to compare the anticipated energy saving of a development-house insula-
IFIAS Member Institutes

Aspen Institute for Humanistic Studies, New York.

Athens Center of Ekistics.

Center for Education in International Management, Geneva.

Center for Theoretical Studies, Miami.

El Colegio de Mexico.

Department of Cell Research and Genetics, Karolinska Institute, Stockholm.

The Graduate Institute of International Studies, Geneva.

Instituto de Biofisica, Rio de Janeiro. International Centre for Theoretical Physics, Trieste.

The International Centre of Insect Physiology and Ecology, Nairobi.

The International Rice Research Institute, Manila.

tion, for example-with the initial energy investment necessary to create the development. The energy impact of recycled materials could be assessed. And industries and governments would be able to examine the energy implications of their decisions.

The second part of the energy project is entitled "Alternative Choices of Level of Energy Consumption in Different Societies". Although it is usually taken for granted that a linear relationship exists between energy consumption per capita and GNP per capita, this is actually true only in energy-affluent societies. The project is analysing why a certain country can achieve the same GNP per capita as another country but with a much lower consumption of energy. The study is aiming at comparative analyses of different socioeconomic trade-offs in different countries (for example Scandinavia, Japan, India, Kenya) at varying levels of energy consumption rates (say $4 \%$, $2 \%$ and $0 \%$ a year).

The project on enzyme engineering is typical of the scope and, in its relevance to developing countries, of the emphasis of IFIAS work. Enzymes are of course already widely used on a 'use-and-throw-away' basis to support a variety of socially necessary processes. But it was not until techniques were developed for immobilising enzymes on a support material that their catalytic activity could be retained for reuse, and this has reawakened interest in the use of enzymes as catalysts in many different areas. The IFIAS project is led by Professor Carl-Göran Hedén of Stockholm's Karolinska Institute and is being carried out by member institutes in France, Israel, India and the USA, as well as other institutes in the USSR, Sweden, Canada and the UK. UNESCO is also participating. The project is investigating the use of enzyme engineering in four fields: developing
The Japan Economic Research Center, Tokyo.

Johnson Research Foundation, Philadelphia.

Mathematics Institute, Coventry.

National Institute for Research Advancement, Tokyo.

Niels Bohr Institute of Physics, Copenhagen.

Institut Pasteur, Paris.

Tata Institute of Fundamental Research, Bombay.

University Corporation for Atmospheric Research, Boulder, Colorado.

The Walter and Eliza Hall Institute of Medical Research, Melbourne.

The Weizmann Institute of Science, Israel.

Woods Hole Oceanographic Institution, Massachusetts.

enzyme-catalysed energy transfer devices which could increase the practical applications of fuel cells or use electrical energy to synthesise organic chemicals for industry, nutrition and pharmaceuticals; testing a quick, enzyme-dependent method of detecting tropical diseases such as malaria; developing a technique of giving the booster shot at the same time as an initial injection in immunisation (to solve the problems of finding people in developing countries when their booster is due); and improving biological control agents by means of enzyme attachment to insect pathogens.

Professor Hedén is enthusiastic about the potential of enzyme engineering in other areas as well. At a symposium in Tokyo last September he outlined an idea which entails a better use of resources for accelerated development in the Middle East. Pointing out that the methods of chemical catalysis currently used in the production of methanol need such high pressures and temperatures that only large-scale factories are competitive, he proposed the use of enzyme catalysis in conjunction with natural methane flares, which today burn as waste, to produce methanol in small-scale plants. Such methanol could be used not only for making fodder protein and enzymes, but also as a cheap, high-octane and relatively clean fuel for cars, or as a safer medium than methane for the carriage of hydrogen.

Such "equilibrium technology"processes and industrial equipment which use renewable energy sources and are geared to a maximum of recycling of matter-is typical of the inventiveness and optimism, some would say idealism, of the IFIAS approach. The attractiveness of Professor Hedén's scheme for the Middle East, for example, does not end with methanol technology. It also emphasises a range 
of biological uses for solar energy ranging from waste treatment to fish farming. He envisages Arab countries such as Kuwait, whose national development plan is very conscious of, and aims for, a balance between ecosystems, providing the vision and financial resources for a regional development effort based on an international input of scientific manpower. This would help to make each side in the Middle East conflict dependent on the other for its future.

As none of IFIAS' projects has yet been completed it is too early to talk about their final results. Already, however, there are signs that IFIAS' work is not going unnoticed. The Brussels headquarters of the Common Market has asked IFIAS for information about the energy analysis programme, and has reserved $\$ 100,000$ for a joint IFIAS/ Common Market project on energy. The Market is particularly interested in adopting IFIAS' methodology for working out alternative levels of energy consumption, with a view to using the technique in drawing up a European energy policy. The World Health
Organisation is also very interested in an IFIAS project; this time the one on enzyme engineering. WHO's attention is concentrated on that part of the project dealing with the new method IFIAS has developed for diagnosing tropical diseases. The method was tested in East Africa last February and looks promising.

The first evaluation of IFIAS will no doubt be the one planned by the organisation itself, to be conducted in 1977-five years after its inception. This idea is good in principle, but should not be expected to produce any rational calculation of its achievements. One of the problems involved is the lack of any concrete output or of any yardstick to measure it. Barring administrative incompetence, each team of institutes will obviously be able to produce lengthy documents supporting the results of its particular project. By then they will also perhaps be able to point to even more examples of their work being referred to by the decision makers.

The continuation of IFIAS will depend not on the results of 'evalua- tions' of its work but on the enthusiasm of its members. And nothing could be calculated to sustain that enthusiasm more than the sort of successes the energy analysis and enzyme engineering projects have already enjoyed. Convincing decision makers of the need for action may be harder in the project on climate change. The invisibility of the problem makes it an unlikely target for that public concern which, in countries where politicians depend on the people for their positions, can be an effective complement to IFIAS' high-level approaches in making the decision makers act. On the other hand, the problems dealt with in the project on human settlements are symbolised by the ugliness, dirtiness and congestion of modern cities. If handled properly, the project could have an impact on public policy. Unfortunately, the impact will be greatest if IFIAS keeps its activities separate from the UN conference towards which they are aimed; for incisive and intelligent proposals have a way of emerging from the politicallysensitive and grindingly slow UN machine in a very emaciated form.
Somenow or other, they had cajoled the money and effort to try their strange and fabulously expensive experiment. Many people said that the funds should be spent on something more useful, or not spent at all. But there was a great public curiosity in the idea; perhaps Orson Welles had helped as much as anyone with his radio broadcast of invaders from Mars in 1938 that caused a nationwide panic. Is there life on Mars? We were now ready to settle for a few anaerobic bacteria rather than green monsters with fusiform antennæ.

The Viking biology team had been called together by the team leader, Harold Klein, for the last time before the launch on August 11, 1975.

One year ago, our hope that even one of the three experiments would be ready by launch-time was a slender one. The constraints were severe; everything that is sent to Mars must be sterile. There is no use carrying bacterial spores from Earth to Mars to detect their presence later. It cost about a million dollars to sterilise the parachute, principally because no-one had ever sterilised a parachute. "Hardy bugs" kept showing up, including one whose spores lived for 6 days at $125^{\circ} \mathrm{C}$. The launch date had to be just right for slinging a shot through the heavens to intercept a planet in conjunction. Worst of all, the instruments were unprecedented in design, infinite in complexity, and strictly limited in size and weight. In engineers' terms, they cost a million dollars per pound; a compacted 20 -kilogram mass of electronic and chemical gadgetry whose price made crown jewels look like dime-store baubles. One of the experiments is called "labeled release". It will incubate a pinch of Martian soil, moistened with water containing radioactively tagged nutrients (formate, glycine, DL alanine, DL lactate and glycolicic acid)

\section{Viking gets ready} from Thomas $H$. Jukes

for two weeks at $6^{\circ}-14^{\circ} \mathrm{C}$, and any emitted gas will be monitored for metabolically-produced radioactivity.

The second is "pyrolytic release", based on the idea that photosynthetic fixation of carbon dioxide, and possibly carbon monoxide, should take place biologically under Martian conditions. The surface sample will be exposed to "artificial sunlight" from a xenon lamp for several days in an atmosphere containing ${ }^{14} \mathrm{CO}_{2}$ and a little ${ }^{14} \mathrm{CO}$. The soil will then be heated to $600{ }^{\circ} \mathrm{C}$ to destroy organic compounds resulting from photosynthesis and the emitted gases will be measured for radioactivity. The experiment is designed also to detect dark fixation of ${ }^{14} \mathrm{CO}_{2}$ and ${ }^{14} \mathrm{CO}$. This experiment is specifically oriented towards Martian organisms that may differ from terrestrial ones in being intolerant of water or "terrestrial nutrients". The third experiment is named "gas exchange" but is often called "the
chicken soup experiment" because it frankly seeks to woo Martian bugs with a rich, non-radioactive meal containing amino acids, vitamins and cofactors, salts and other nutrients, from kitchens on the Earth. The soil sample is moistened with the culture medium, and the atmosphere in the chamber, mostly helium, is periodically analysed by gas chromatography to see if gases such as methane and $\mathrm{CO}_{2}$ are emitted.

At the meeting on June 17, the engineers from Thompson-Ramo-Wooldridge and Martin-Marietta appropriately handed us a glossary of 80 acronyms to help us follow their talks. The mood was one of relief, and guarded optimism. All three of the experimental instruments, miraculously, had come into working order at the last minute. The Viking Biology package, in duplicate, had been loaded into two spacecraft at the Kennedy Space Center in Florida. All that now remains is that the instruments should survive the launches on August 11 and 21 , the eleven-month, 450-million-mile journey, and the "soft" landings through the thin (5 millibars) $\mathrm{CO}_{2}$ atmosphere of Mars in July 1976.

After that, perhaps, the faintly-whispered signals will tell us what is happening; not only in the biology package but in the colour cameras, the water detector, the infra-red thermal mapper, the gas-chromatograph-mass - spectrometer, the X-ray fluorescence spectrometer, the seismometer and the weather station. But a main worry is: if the signals next year say that life may be present, will people believe the message? 